\title{
Assessment of strain and mechanical dyssynchrony indices in single ventricle populations by cardiac magnetic resonance feature-tracking techniques
}

\author{
Ryan A Moore ${ }^{1 *}$, Michael Taylor ${ }^{1}$, Wojciech Mazur ${ }^{2}$, Kan N Hor ${ }^{1}$ \\ From 16th Annual SCMR Scientific Sessions \\ San Francisco, CA, USA. 31 January - 3 February 2013
}

\section{Background}

Single ventricle (SV) physiology consists of a single pumping chamber that provides both systemic and pulmonary blood flow. The typical quantitative measurements of ventricular function (i.e. ejection fraction) cannot be accurately applied to single ventricles due to abnormal ventricular morphology. Cardiac Magnetic Resonance (CMR) has become a leading diagnostic tool in the assessment of ventricular mechanics in patients with abnormal ventricular morphology. CMR feature-tracking (FT) techniques allow for the analysis of circumferential strain $(\varepsilon \mathrm{cc})$, longitudinal strain (ell), and mechanical dyssynchrony indices (MDI). We hypothesize that evidence of declining $\varepsilon \mathrm{cc}, \varepsilon l$, and MDI by CMR will be a early biomarker of ventricular dysfunction in SV patients.

\section{Methods}

CMR data was obtained from 25 control subjects (Group A) and $30 \mathrm{SV}$ patients (Group B and C). Control patients were defined as those with a clinical CMR that yielded a normal result. SV groups included patients with single right ventricles (SRV) and single left ventricles (SLV). SV patients were divided into those with normal EF $\geq 55 \%$ (Group B) and those with abnormal EF $<55 \%$ (Group C). Standard imaging data included steady-state free precession (SSFP) short-axis cine stack images sequences. Analysis was performed using QMASS ${ }^{\circledR}$ for ventricular function and $\mathrm{TomTec}^{\circledR}$ feature-tracking for strain analysis and mechanical dyssynchrony. EF and ecc data was tabulated in the preliminary data set (ell and MDI data pending). Preliminary statistical analysis was performed via Student's t-test.

\section{Results}

CMR data was reviewed and analyzed in $30 \mathrm{SV}$ patients (mean age $17.5 \pm 13.3$ years) and 25 control subjects (mean age $15.6 \pm 9.4$ years) $(\mathrm{p}=\mathrm{NS})$. Controls (Group A) had normal EF $(64.7+/-4.8)$ and $\varepsilon \mathrm{CC}(-18+/-1.6)$. $\varepsilon \mathrm{cc}$ was worse in both SV groups (B and C) compared to controls (A) $(\mathrm{p}<0.0001)$. Compared to age-matched controls (A), SV patients with normal EF (Group B) had worse ecc $(-14.6+/-2.1)$. SV patients with decline in $\mathrm{EF}<55 \%$ (Group C) had a continued decline in $\varepsilon \mathrm{cc}(-10.6+/-3.7)$ compared to to SV patients with normal EF $(\mathrm{p}<0.01)$. Longitudinal strain and mechanical dyssynchrony data are currently being obtained.

\section{Conclusions}

ECC in SV patients is abnormal despite normal EF and provides a more sensitive method of assessing subtle ventricular dysfunction in patients with abnormal ventricular morphology. Longitudinal strain and mechanical dyssynchrony indices may provide additional measures of ventricular dysfunction in SV patients based on specific type of defect and allow for further delineation of SV groups.

\section{Funding}

No financial disclosures. 


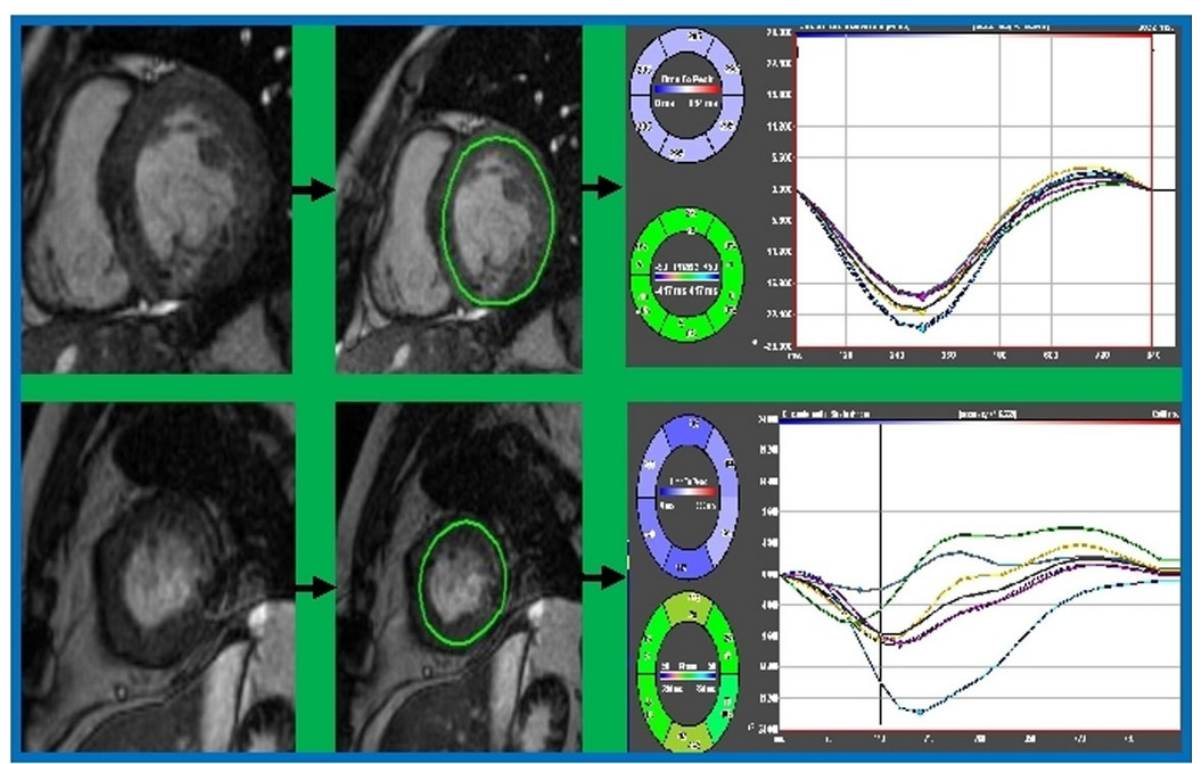

Figure 1 Sample images from SSFP feature tracking analysis of normal control (top panel) and SV patient (bottom panel).

\section{Author details}

${ }^{1}$ Cardiology, Cincinnati Children's Medical Center, Cincinnati, OH, USA.

${ }^{2}$ Cardiology, The Christ Hospital, Cincinnati, OH, USA.

Published: 30 January 2013

doi:10.1186/1532-429X-15-S1-E89

Cite this article as: Moore et al:: Assessment of strain and mechanical

dyssynchrony indices in single ventricle populations by cardiac

magnetic resonance feature-tracking techniques. Journal of

Cardiovascular Magnetic Resonance 2013 15(Suppl 1):E89.

\section{Submit your next manuscript to BioMed Central} and take full advantage of:

- Convenient online submission

- Thorough peer review

- No space constraints or color figure charges

- Immediate publication on acceptance

- Inclusion in PubMed, CAS, Scopus and Google Scholar

- Research which is freely available for redistribution

Submit your manuscript at www.biomedcentral.com/submit 